\title{
Development and validation of a reversed-phase HPLC method for determination of assay content of Teriflunomide by the aid of BOMD simulations
}

\author{
Abolghasem Beheshtia,b, Zahra Kamalzadeh ${ }^{a}$, Monireh Haj-Malek ${ }^{a}$, Meghdad Payab ${ }^{a}$, \\ Mohammad Amin Rezvanfar ${ }^{\mathrm{a}}$ and Seyyed Amir Siadatia ${ }^{*}$
}

${ }^{a} R \& D$ Department, Tofigh Daru Research and Engineering Company, TPICO, Tehran, Iran ${ }^{b}$ Department of Chemistry, Payame Noor University, Tehran, Iran

\begin{tabular}{l} 
C H R O N I C L E \\
\hline Article history: \\
Received November 18, 2020 \\
Received in revised form \\
March 10, 2021 \\
Accepted March 10, 2021 \\
Available online \\
March 10, 2021 \\
\hline Keywords: \\
Teriflunomide \\
BOMD \\
TD-DFT \\
HPLC \\
Method Validation
\end{tabular}

\begin{abstract}
A B S T R A C T
Due to the new hopes for treatment of multiple sclerosis (MS) diseases by Teriflunomide (TFN), in this project, a cheap, robust, and fully validated method has been developed both for determination of assay content in API (active pharmaceutical ingredient), and for related impurities analysis (RIA). To operate the method, a common C18, end-capped $(250 \times 4.6)$ $\mathrm{mm}, 5 \mu \mathrm{m}$ liquid chromatography column, was applied. The mobile phase A was prepared by dissolving $2.74 \mathrm{~g}(20 \mathrm{mM})$ of PDP (potassium dihydrogen phosphate) and $3.72 \mathrm{~g}(50 \mathrm{mM})$ of PC (potassium chloride) in water $(1000 \mathrm{~mL})$. Then, $\mathrm{pH}$ was adjusted to 3.0 by adding OPA (ortho-phosphoric acid) $85 \%$; while, the mobile phase B was acetonitrile (ACN) $(100 \%)$. In order to confirm the experimental data about the $\lambda \max$ of TFN, we have used the BornOppenheimer molecular dynamics (BOMD) simulations, quantum mechanics (QM), and TDDFT calculations. According to the results, the method showed a high level of suitability, specificity, linearity, accuracy, precision, repeatability, robustness, and reliable detection limit.
\end{abstract}

(C) 2021 Growing Science Ltd. All rights reserved.

\section{Introduction}

Multiple sclerosis (MS), the complexneurological immune-mediated disease has poorly been understood (especially in view of aetiology). Among all complex disorders, MS which is caused by the interaction of genetic and environmental factors, has endangered the human race. ${ }^{1}$ For many decades, scientists tried to find an appropriate method for treating the MS patients. Due to this, different type of drugs, based on peptides, ${ }^{2}$ heterocyclic compounds, ${ }^{3}$ and other materials ${ }^{4}$ were introduced as cures for this vital disease. Teriflunomide (TFN), along with, Glatiramer acetate, and Fingolimod are of the first line treatment of MS in the USA and Australia. ${ }^{2-4}$ Also, TFN has been characterized by a once daily oral Prescription medication for the treatment, and a comparably well-established long-term safety profile. $^{5}$ TFN is the active metabolite of leflunomide, and it had been investigated in the Phase III clinical trial TEMSO as a medication for MS disease. In 2012, the study was completed with positive results; while, the subsequent comparison of trial reported that permanent discontinuations were 
substantially less common among MS patients who received teriflunomide compared with interferon beta-1a. ${ }^{6}$ Finally, in 2012, the drug was approved by the FDA, and subsequently some of the other pharmacopeias permitted the use of that. ${ }^{7}$ Then, pharmaceutical companies considered the use of TFN, and industrial researchers began to find suitable methods for analyzing this drug.

In 2010, Sobhani and colleagues designed a HPLC method containing $10 \mathrm{mM}$ PDP and $100 \mathrm{mM}$ $\mathrm{PC}$ in aqueous $25 \% \mathrm{ACN}$, acidified to $\mathrm{pH} 3$ with o-phosphoric acid, for assay analysis of the leflunomide metabolite, teriflunomide. ${ }^{8}$ In 2017, Mehta et al, developed a HPLC separation method for estimation of TFN in API by using an Agilent-1260 Infinity series instrument with Eclipse XBD C18

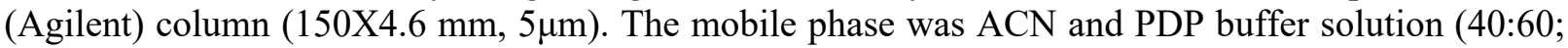
$\mathrm{v} / \mathrm{v}$ ) containing TEA (triethyl amine) to $\mathrm{pH} \mathrm{7}$, and the flow rate was $1.0 \mathrm{ml} / \mathrm{min}$. The method had been validated for specificity, linearity, precision, accuracy, robustness and ruggedness. ${ }^{9}$ In one of the other reports, Rakhila and co-workers developed a method composed of $0.5 \mathrm{mM}$ ammonium acetate in a mixture of water, $\mathrm{ACN}$, and formic acid with a volume ratio of 95:5:0.02, respectively. The flow rate was $0.5 \mathrm{~mL} / \mathrm{min}$ and the temperature of the column oven was $25^{\circ} \mathrm{C} .{ }^{10}$ It should be noted that such accurate heterocyclic synthesis of such bioactive drugs is the result of years of attempts in different types of methodologies ${ }^{11,12}$ and heterocyclic ${ }^{13-15}$ organic synthesis. Also, the theoretical chemical calculations used in this project, to confirm the experimental results, have been widely applied ${ }^{16-18}$ to give more trustable results.

Regarding these, in this project, a cheap, robust, and fully validated method has been developed both for determination of assay content in API, and for RIA test. Compared to the previous methods, the represent approach, which has used UV-Visible detector at $280 \mathrm{~nm}$, shows a higher level of suitability, specificity, linearity, accuracy, precision, repeatability, and robustness, both for related separation, and assay analysis. Thus, it was suitable for use in pharmaceutical companies.

\section{Results and Discussion}

The present method showed a high level of validity using mobile phase A which was prepared by dissolving $2.74 \mathrm{~g}(20 \mathrm{mM})$ of PDP and $3.72 \mathrm{~g}(50 \mathrm{mM})$ of PC in water to $\mathrm{pH} 3$, and the mobile phase B which was ACN (100\%). In addition, the gradient elution program was $(75 \%, 0.00),(55 \%, 30.00)$, and $(55 \%, 60.00)$ (mobile phase A\%, time(min), respectively (Table 1). In the following sections, we have presented the suitability, specificity, linearity, accuracy, precision, repeatability, robustness, and reliable detection limit.

Table 1. The gradient elution program of the analysis

\begin{tabular}{cccc}
\hline No. & Time (min) & $\begin{array}{c}\text { Mobile phase A } \\
\text { (percent V/V) }\end{array}$ & $\begin{array}{c}\text { Mobile phase B } \\
\text { (percent V/V) }\end{array}$ \\
\hline $\mathbf{1}$ & 0.00 & 75 & 25 \\
$\mathbf{2}$ & 30.00 & 55 & 45 \\
$\mathbf{3}$ & 60.00 & 55 & 45 \\
\hline
\end{tabular}

\subsection{Theoretical section}

To find the best absorption area $\left(\lambda_{\max }\right)$ of TFN (and setting the detector in the method), first, we have used the Born-Oppenheimer molecular dynamic (BOMD) simulation (see Figure 1). This simulation method helps to find the more stable states of the molecular systems for further quantum mechanics optimizations. 


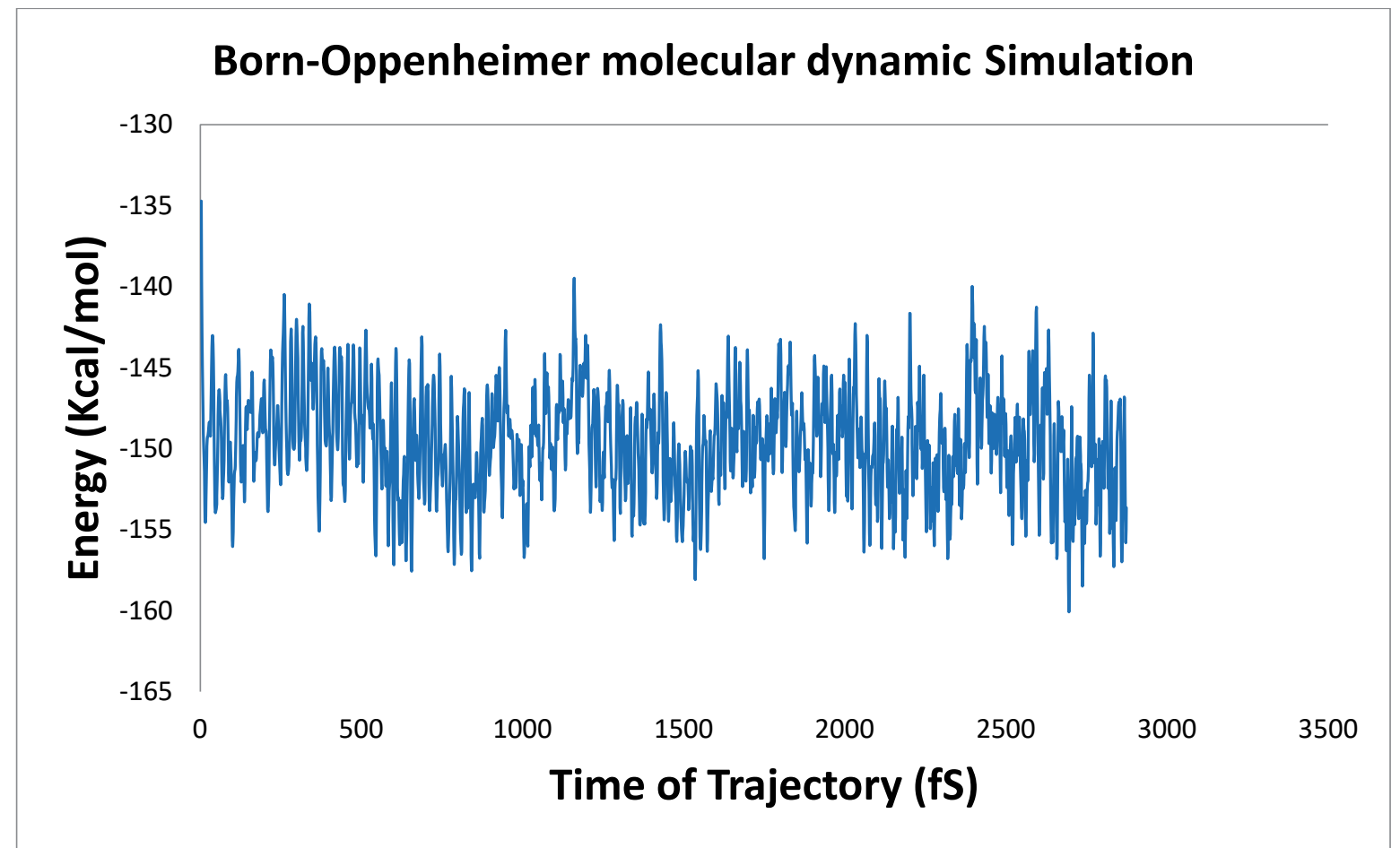

Fig. 1. The Born-Oppenheimer molecular dynamic (BOMD) simulation spectrum for TFN molecular system

Then, some of the more stable states are being used as input files for optimization (in this case we have used the B3LYP/6311G(d,p) level of theory to reach more trustable data). Finally, the output geometrical system of the optimization process which shows one of the best orientations, would undergo the TD-DFT job to give the UV-Visible absorption spectrum of the molecule. As shown in Fig. 2, the best UV-visible absorption area for TFN molecules is about $300 \mathrm{~nm}$, which is in agreement with the experimental results. Indeed, in the present project, we have used the B3LYP/6311G(d,p) level of theory, both for optimization (to find the energy minima) and for TD-DFT calculation in order to reach the infrared spectrum.

\section{UV Visible Spectrum}

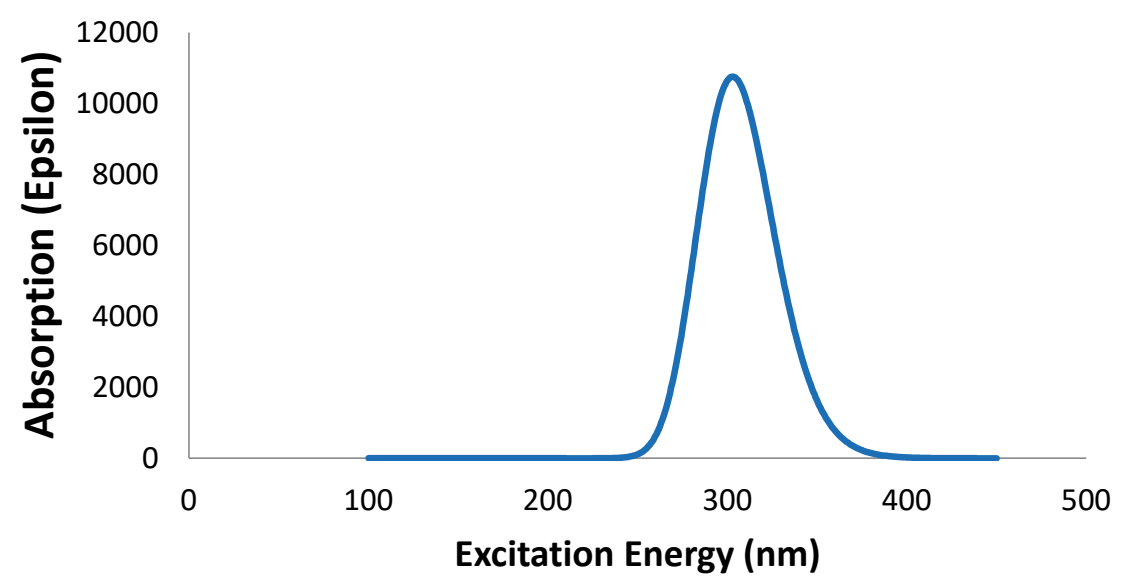

Fig. 2. The TD-DFT UV-visible absorption spectrum of the optimized structure of TFN, calculated at B3LYP/6-311G(d,p) level of theory. 


\subsection{Method development and validation}

Due to the fact that in pharmaceutical companies, any error may endanger the human lives, development and validation ${ }^{19}$ of analytical methods (in any aspect) especially in the case of instrumental methods is very important. Thus, the present designed method was investigated in the case of validations.

\subsubsection{Sample preparation}

Stock solution was prepared by dissolving $0.01561 \mathrm{~g}$ of TFN standard in $50.0 \mathrm{~mL}$ of diluents. Then, solutions with different concentrations were prepared accordingly.

\subsubsection{Equipment}

A Shimadzu Prominence system (Shimadzu Corporation, Kyoto, Japan) Equipped with a LC20AD pump, a DGU-20A degassing system, a CTO-20A column oven and a SPD-20A UV-Vis detector, was used for all analysis. The LabSolutions software version 5.51 was applied for processing and data analysis. Also, the chromatography column was a C18, end-capped with 250mm in length, 4.6 $\mathrm{mm}$ in internal diameter, and $5 \mu \mathrm{m}$ in pore size.

\subsubsection{System suitability}

In order to study the suitability of the method, the standard solution of TFN was spiked with the appropriate level of Leflunomide (as a known impurity of TFN) and then, the system suitability parameters were studied. As given in Table 2, the percentage of the RSD values for the area and RT of TFN peaks for five injections were not more than $2.0 \%$. Moreover, the tailing factor (TF), resolution between peaks, and the number of theoretical plates (NTP), are less than 2.0, more than 2.0 and more than 2000, respectively, which show the suitability of the system (Table 2). The resolution between TFN and Leflunomide peaks should not be less than 20 (due to high resolutions, given in Table 2).

Table 2. System suitability parameters for the developed method of TFN

\begin{tabular}{cccccc}
\hline \multicolumn{7}{c}{ TFN $\mathbf{( 0 . 9 9 3} \mathbf{~ m g} / \mathbf{L})$} \\
\hline Run\# & RT & Area & Tailing factor & NTP & *Resolution \\
\hline $\mathbf{1}$ & 22.390 & 73733 & 1.166 & 15301 & 23.042 \\
$\mathbf{2}$ & 22.390 & 73997 & 1.153 & 14658 & 22.534 \\
$\mathbf{3}$ & 22.388 & 73891 & 1.161 & 15128 & 22.787 \\
$\mathbf{5}$ & 22.388 & 73434 & 1.139 & 14718 & 22.407 \\
Average & 22.380 & 73824 & 1.144 & 14907 & 22.571 \\
\hline \% RSD & 22.387 & 73775.800 & 1.153 & 14942.400 & 22.668 \\
\hline
\end{tabular}

*Resolution between TFN and Leflunomide peaks.

\subsubsection{Specificity}

ICH documents ${ }^{20}$ define the specificity parameter as the ability to assess unequivocally the analyte in the presence of components, which could be presented. Typically, these might include impurities, degradants, matrix, etc. in this regard, the peak purity tests may be useful to show that the analyte chromatographic peak is not attributable to more than one component (like diode array, or mass spectrometry). Herein, the peak purity was studied by using a PDA detector, and the absorbance spectrums of TFN in the upslope, apex and downslope of the chromatographic peak were compared 
accordingly. As could be observed, there is not a significant difference between the spectrums. Also, the standard solution of TFN was spiked with the appropriate level of known Leflunomide and the resolution between those two was presented in Table 3. The results revealed no peak interference with the TFN peak, therefore the specificity of the method was confirmed (Fig. 3).

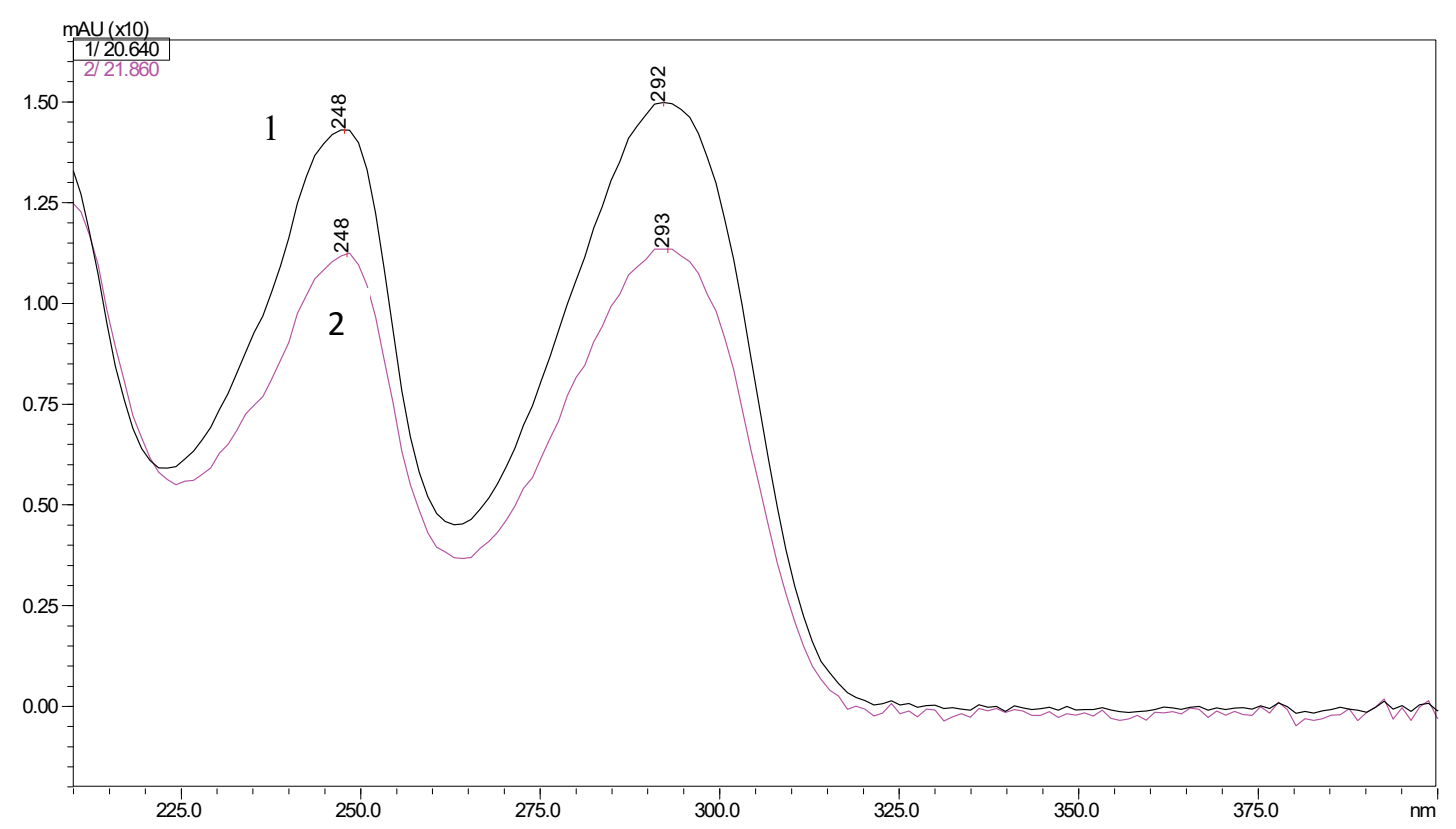

Fig. 3. Absorbance spectrums of $\mathrm{TFN}$ at $\mathrm{RT}=20.64 \mathrm{~min}$ (upslope) and $\mathrm{RT}=21.86 \mathrm{~min}$ (downslope)

\subsubsection{Linearity}

To investigate the linearity of the method, the solutions of TFN standard were injected according to Table 4 (each solution was injected three times). A linear calibration curve (Fig. 4) was achieved by plotting the average analytical signal versus the concentration of TFN standard, and then, the regression line was calculated by the method of least squares. Data presented in Table 3, and Fig. $\mathbf{4}$ show that the coefficient of determination $\left(\mathrm{R}^{2}\right)$ is about 0.9991 , which indicates the high level of linearity of the method (limit: the coefficient of determination $\left(\mathrm{R}^{2}\right)$ should not be less than 0.998).

Table 3. Calibration curve data to give the linearity parameters

\begin{tabular}{|c|c|c|c|c|c|c|}
\hline Solution & Conc. $(\mathrm{mg} / \mathrm{L})$ & Run1 & Run2 & Run3 & Average & $\%$ RSD \\
\hline S1 & 0.311 & 21407 & 21742 & 21682 & 21610.333 & 0.827 \\
\hline S2 & 0.622 & 46572 & 46428 & 46417 & 46472.333 & 0.186 \\
\hline S3 & 0.777 & 59435 & 59561 & 59682 & 59559.333 & 0.207 \\
\hline S4 & 1.036 & 80253 & 79853 & 80570 & 80225.333 & 0.448 \\
\hline S5 & 1.244 & 93822 & 93512 & 93211 & 93515 & 0.327 \\
\hline S6 & 1.555 & 119603 & 119023 & 119954 & 119526.667 & 0.393 \\
\hline \multicolumn{4}{|c|}{ Regression equation } & \multicolumn{3}{|c|}{$y=78113.779 x-2035.290$} \\
\hline \multicolumn{4}{|c|}{ Coefficient of determination $\left(\mathrm{R}^{2}\right)$} & \multicolumn{3}{|c|}{0.9991} \\
\hline \multicolumn{4}{|c|}{ Lower concentration $(\mathrm{mg} / \mathrm{L})$} & \multicolumn{3}{|c|}{0.311} \\
\hline \multicolumn{4}{|c|}{ Upper concentration $(\mathrm{mg} / \mathrm{L})$} & \multicolumn{3}{|c|}{1.555} \\
\hline
\end{tabular}




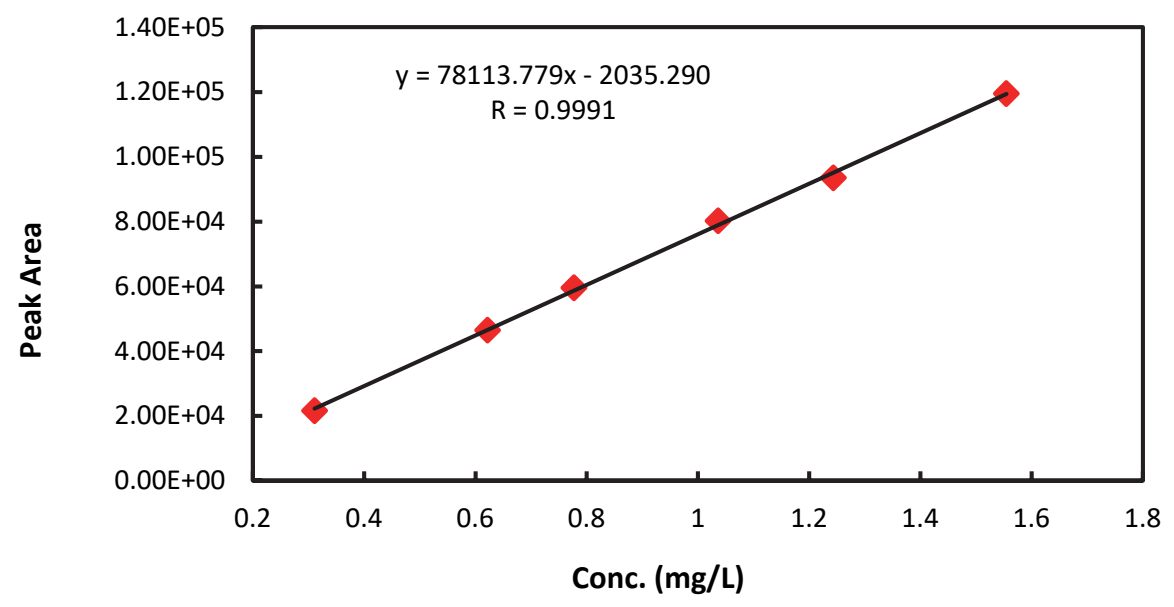

Figure 4. Calibration curve for the linearity analysis of the TFN method.

\subsubsection{Detection Limit and Quantitation Limit}

As given in literature, the detection limit (DL) of an individual analytical method is the lowest possible amount of analyte in a sample which could be detected; while, it is not necessarily quantitated as an exact value. Also, the quantitation limit (QL) of an individual analytical approach is the lowest amount of analyte in a sample which could be quantitatively determined with a suitable level of precision and accuracy. As shown in following, in this study, DL and QL were determined based on the standard deviation of the $y$-intercept and the slope of the calibration curve. ${ }^{21}$

The DL and QL were expressed as (Eq. (1) and Eq. (2)):

$$
\begin{aligned}
& L O D=\frac{3.3 \sigma}{S} \\
& L O Q=\frac{10 \sigma}{S}
\end{aligned}
$$

where, $\sigma$ is the standard deviation of $\mathrm{y}$-intercept, and $\mathrm{S}$ is the slope of the calibration curve.

The DL and QL values were presented in Table 4.

Table 4. DL and QL values calculated for examining the validity of the method

\begin{tabular}{cc} 
Slope & 78113.779 \\
Standard deviation of y-intercept & 1179.141 \\
DL (mg/L) & 0.050 \\
QL (mg/L) & 0.151 \\
\hline
\end{tabular}

As presented in Table 5, the sample known to be near the DL, was reliably detected. Also, the sample known to be near the QL, was quantitatively determined with suitable precision and accuracy. The results show that the amounts of DL, and QL are $0.052 \mathrm{ppm}$, and $0.155 \mathrm{ppm}$, respectively, which indicate that the method is pretty sensitive. The DL, and QL parameters should not be more than 0.06 , and 0.2 , respectively. In addition, the recovery $\%$ should be between $98 \%$ to $102 \%$. 
Table 5. Validation of the DL and QL values for the developed TFN method

\begin{tabular}{cccccccc}
\hline $\begin{array}{c}\text { Conc. } \\
(\mathbf{m g} / \mathbf{L})\end{array}$ & Run1 & Run2 & Run3 & Average & \% RSD & $\begin{array}{c}\text { Found Conc. } \\
(\mathbf{m g} / \mathbf{L})\end{array}$ & Recovery\% \\
\hline 0.155 & 10382 & 10257 & 10220 & 10286.333 & 0.825 & 0.158 & 101.466 \\
0.052 & 3091 & 3075 & 3098 & 3088 & 0.382 & -- & -- \\
\hline
\end{tabular}

\subsubsection{Accuracy}

The accuracy of the present developed method has been evaluated by means of analyzing standard samples of TFN at three concentration levels with three independent sample preparations (Table 6). The recovery percentages were calculated regarding the regression equation. The results show that the recovery data are in the acceptable range of $98.0-102.0 \%$.

Table 6. The results of the Accuracy calculations of the developed TFN method

\begin{tabular}{cccccccc}
\hline Sample & Conc. (mg/L) & Run1 & Run2 & Run3 & Average & Found Conc. (mg/L) & \% Recovery \\
\hline $\mathbf{1}$ & 0.681 & 51455 & 51655 & 51789 & 51633.000 & 0.687 & 100.860 \\
$\mathbf{2}$ & 0.680 & 50740 & 51007 & 50945 & 50897.333 & 0.678 & 99.623 \\
$\mathbf{3}$ & 0.679 & 50646 & 50936 & 50842 & 50808.000 & 0.677 & 99.674 \\
\hline $\mathbf{1}$ & 0.908 & 68052 & 68562 & 68699 & 68437.667 & 0.902 & 99.331 \\
$\mathbf{2}$ & 0.907 & 68721 & 69000 & 68743 & 68821.333 & 0.907 & 100.018 \\
$\mathbf{3}$ & 0.905 & 68278 & 68278 & 67825 & 68127.000 & 0.898 & 99.256 \\
\hline $\mathbf{1}$ & 1.362 & 104025 & 104790 & 104017 & 104277.333 & 1.361 & 99.898 \\
$\mathbf{2}$ & 1.360 & 103912 & 104224 & 104729 & 104288.333 & 1.361 & 100.054 \\
$\mathbf{3}$ & 1.357 & 103422 & 103880 & 103891 & 103731.000 & 1.354 & 99.749 \\
\hline
\end{tabular}

\subsubsection{Precision}

Due to the literature, the precision of an analytical method is defined as the closeness of agreement between a series of measurements obtained from multiple sampling of the same homogeneous sample under the defined conditions. Thus, the precision is the standard deviation, variance, or coefficient of variation of a series of measurements. ${ }^{22}$

\subsubsection{Repeatability (Intra-day precision)}

Repeatability of the method was assessed via analyzing the standard samples of TFN at $100 \%$ of the test concentration with six independent sample preparations. As given in Table 6 , the $\%$ RSD values for TFN responses are less than $0.2 \%$ which could be acceptable (Table 7).

Table 7. Intra-day precision of the method on the first day

\begin{tabular}{ccccccc}
\hline Sample\# & Conc. $(\mathbf{m g} / \mathbf{L})$ & Run1 & Run2 & Run3 & Average & \% RSD \\
\hline $\mathbf{1}$ & 1.012 & 76720 & 76669 & 76723 & 76704 & 0.040 \\
$\mathbf{2}$ & 1.014 & 77754 & 77723 & 77854 & 77777 & 0.088 \\
$\mathbf{3}$ & 1.013 & 77657 & 77554 & 77820 & 77677 & 0.173 \\
$\mathbf{4}$ & 1.012 & 76750 & 76996 & 76740 & 76828.667 & 0.189 \\
$\mathbf{5}$ & 1.013 & 77509 & 77517 & 77439 & 77488.333 & 0.055 \\
$\mathbf{6}$ & 1.014 & 77083 & 77331 & 77255 & 77223 & 0.165 \\
\hline
\end{tabular}


Table 8. Intra-day precision of the method on the second day.

\begin{tabular}{ccccccc}
\hline Sample\# & Conc. $(\mathbf{m g} / \mathbf{L})$ & Run1 & Run2 & Run3 & Average & \% RSD \\
\hline $\mathbf{1}$ & 1.013 & 77627 & 77517 & 77481 & 77541.667 & 0.098 \\
$\mathbf{2}$ & 1.013 & 78097 & 78036 & 78044 & 78059 & 0.042 \\
$\mathbf{3}$ & 1.014 & 78409 & 78451 & 78213 & 78357.667 & 0.162 \\
$\mathbf{4}$ & 1.012 & 76948 & 76849 & 76878 & 76891.667 & 0.066 \\
$\mathbf{5}$ & 1.014 & 77896 & 77768 & 77855 & 77839.667 & 0.084 \\
$\mathbf{6}$ & 1.013 & 77325 & 77246 & 77190 & 77253.667 & 0.088 \\
\hline
\end{tabular}

As could be observed in Table 7 and Table 8, the intraday precision of the developed method does not significantly change between different days, and different instrument.

\subsubsection{Intermediate precision}

To investigate the intermediate precision, the standard samples of TFN at $100 \%$ of the test concentration (with six independent sample preparations on each day) were prepared by two different analysts and were analyzed by using two different columns. The results showed that the \% RSD values for TFN responses are about $0.551,0.656$, and 0.947 for the first, second, and third days, respectively, which are less than $2.0 \%$ showing to be acceptable (the related tables are presented in the supplementary data).

\subsubsection{Robustness study}

To perform the robustness study on the developed method, a standard solution of TFN (which was spiked with the appropriate level of Leflunomide (its known impurity)) was used. During the study, the flow rate, column temperature and $\mathrm{pH}$ of the mobile phase A (buffer) were changed and the amount of change of the response was calculated, accordingly. As given in Tables 9,10 , and 11, by small changes in column temperature $\left(-0.201 \%\right.$, and $0.159 \%$ changes in area for $33^{\circ} \mathrm{C}$, and $37^{\circ} \mathrm{C}$, respectively) and in $\mathrm{pH}(-0.759 \%$, and $-0.298 \%$ changes in area for $\mathrm{pHs} 2.8$, and 3.2, respectively), the amount of change of the peak area was less than $\pm 2.0 \%$. However, the results presented in Table 7 revealed that small changes in the mobile phase flow rate $(4.933 \%$, and $-4.206 \%$ changes in area for $0.95 \mathrm{ml} / \mathrm{min}$, and 1.05 $\mathrm{ml} / \mathrm{min}$ respectively) can significantly affect the peak response. Thus, it is necessary to ensure that the HPLC pump operates properly and correctly.

Table 9. The effect of column temperature on the peak response of the developed method

\begin{tabular}{|c|c|c|c|c|c|c|}
\hline \multicolumn{7}{|c|}{ TFN (0.993 mg/L) } \\
\hline \multirow{3}{*}{ Run } & \multicolumn{6}{|c|}{ Column temperature } \\
\hline & \multicolumn{2}{|c|}{$\mathrm{T}=3^{\circ}{ }^{\circ} \mathrm{C}$} & \multicolumn{2}{|c|}{$\mathrm{T}=\mathbf{3 5}^{\circ} \mathrm{C}$} & \multicolumn{2}{|c|}{$\mathbf{T}=37^{\circ} \mathrm{C}$} \\
\hline & RT & Area & RT & Area & RT & Area \\
\hline 1 & 22.715 & 73651 & 22.390 & 73733 & 22.024 & 73733 \\
\hline 2 & 22.769 & 73756 & 22.388 & 73434 & 22.046 & 73690 \\
\hline 3 & 22.688 & 73140 & 22.380 & 73824 & 22.046 & 73919 \\
\hline Average & 22.724 & 73515.667 & 22.386 & 73663.667 & 22.039 & 73780.667 \\
\hline$\%$ RSD & 0.181 & 0.448 & 0.019 & 0.290 & 0.058 & 0.165 \\
\hline Average of TF & \multicolumn{2}{|c|}{1.156} & \multicolumn{2}{|c|}{1.153} & \multicolumn{2}{|c|}{1.145} \\
\hline Average of NTP & \multicolumn{2}{|c|}{15283.333} & \multicolumn{2}{|c|}{14942.400} & \multicolumn{2}{|c|}{15222.333} \\
\hline Average of * Resolution & \multicolumn{2}{|c|}{23.339} & \multicolumn{2}{|c|}{22.668} & \multicolumn{2}{|c|}{23.956} \\
\hline$\%$ Change of peak area & \multicolumn{2}{|c|}{-0.201} & \multicolumn{2}{|c|}{--- } & \multicolumn{2}{|c|}{0.159} \\
\hline
\end{tabular}

*Resolution between TFN and Leflunomide peaks. 
Table 10. The effect of $\mathrm{pH}$ of the mobile phase A on the peak response of the developed method.

\begin{tabular}{|c|c|c|c|c|c|c|}
\hline \multicolumn{7}{|c|}{ TFN (0.993 mg/L) } \\
\hline \multirow{3}{*}{ Run\# } & \multicolumn{6}{|c|}{ pH of mobile phase $A$} \\
\hline & \multicolumn{2}{|c|}{$\mathrm{pH}=2.8$} & \multicolumn{2}{|c|}{$\mathrm{pH}=\mathbf{3 . 0}$} & \multicolumn{2}{|c|}{$\mathrm{pH}=3.2$} \\
\hline & RT & Area & RT & Area & RT & Area \\
\hline 1 & 22.899 & 73078 & 22.390 & 73733 & 21.311 & 73548 \\
\hline 2 & 22.839 & 73095 & 22.388 & 73434 & 21.309 & 73430 \\
\hline 3 & 22.802 & 73141 & 22.380 & 73824 & 21.274 & 73355 \\
\hline Average & 22.847 & 73104.667 & 22.386 & 73663.667 & 21.298 & 73444.333 \\
\hline$\%$ RSD & 0.214 & 0.044 & 0.019 & 0.290 & 0.098 & 0.132 \\
\hline Average of TF & \multicolumn{2}{|c|}{0.770} & \multicolumn{2}{|c|}{1.153} & \multicolumn{2}{|c|}{1.129} \\
\hline Average of NTP & \multicolumn{2}{|c|}{19399.333} & \multicolumn{2}{|c|}{14942.400} & \multicolumn{2}{|c|}{13698.667} \\
\hline Average of *Resolution & \multicolumn{2}{|c|}{28.005} & \multicolumn{2}{|c|}{22.668} & \multicolumn{2}{|c|}{24.724} \\
\hline$\%$ Change of peak area & \multicolumn{2}{|c|}{-0.759} & \multicolumn{2}{|c|}{--- } & \multicolumn{2}{|c|}{-0.298} \\
\hline
\end{tabular}

*Resolution between TFN and Leflunomide peaks.

Table 11. The effect of the mobile phase flow rate on the peak response of the developed method

TFN (0.993 mg/L)

\begin{tabular}{|c|c|c|c|c|c|c|}
\hline \multirow{3}{*}{ Run\# } & \multicolumn{6}{|c|}{ Flow rate $(\mathrm{mL} / \mathrm{min})$} \\
\hline & \multicolumn{2}{|c|}{$F=0.95$} & \multicolumn{2}{|c|}{$F=1.0$} & \multicolumn{2}{|c|}{$F=1.05$} \\
\hline & RT & Area & RT & Area & RT & Area \\
\hline 1 & 23.104 & 77178 & 22.390 & 73733 & 21.813 & 70721 \\
\hline 2 & 23.114 & 77568 & 22.388 & 73434 & 21.819 & 70541 \\
\hline 3 & 23.121 & 77147 & 22.380 & 73824 & 21.831 & 70434 \\
\hline Average & 23.113 & 77297.667 & 22.386 & 73663.667 & 21.821 & 70565.333 \\
\hline$\%$ RSD & 0.037 & 0.303 & 0.019 & 0.290 & 0.042 & 0.206 \\
\hline Average of TF & \multicolumn{2}{|c|}{1.153} & \multicolumn{2}{|c|}{1.153} & \multicolumn{2}{|c|}{1.129} \\
\hline Average of NTP & \multicolumn{2}{|c|}{15138} & \multicolumn{2}{|c|}{14942.400} & \multicolumn{2}{|c|}{13842.667} \\
\hline $\begin{array}{c}\text { Average of } \\
* \text { Resolution }\end{array}$ & \multicolumn{2}{|c|}{22.411} & \multicolumn{2}{|c|}{22.668} & \multicolumn{2}{|c|}{23.047} \\
\hline $\begin{array}{c}\text { \% Change of peak } \\
\text { area } \\
\end{array}$ & \multicolumn{2}{|c|}{4.933} & \multicolumn{2}{|c|}{---} & \multicolumn{2}{|c|}{-4.206} \\
\hline
\end{tabular}

*Resolution between TFN and Leflunomide peaks.

According to the results, the method showed a high level of suitability, specificity, linearity, accuracy, precision, repeatability, robustness, and reliable detection limit.

\section{Conclusions}

In the case of specificity, the results show that there is not a significant difference between the spectrums of TFN. Also, the standard solution of TFN was spiked with the appropriate level of known Leflunomide and the resolution between those two was generally high. The results revealed no peak interference with the TFN peak, therefore the specificity of the method was confirmed. The Data, which were achieved by calibration curve, show that the coefficient of determination $\left(\mathrm{R}^{2}\right)$ is about 0.9991 . It indicates the high level of linearity of the method. Also, in the case of the detection limits, the results showed that the amounts of DL, and QL were $0.052 \mathrm{ppm}$, and $0.155 \mathrm{ppm}$, respectively, which indicated that the method is pretty sensitive. Moreover, the results showed that the recovery data obtained within 
the acceptable range of $98.0-102.0 \%$. On the other hand, the repeatability of the method was studied via analyzing the standard samples of TFN at $100 \%$ of the test concentration with six independent sample preparations. The results showed that the percentage of the RSD values for TFN responses are less than $0.2 \%$ which could be acceptable. Finally, the results showed that by small changes in column temperature $\left(-0.201 \%\right.$, and $0.159 \%$ changes in area for $33^{\circ} \mathrm{C}$, and $37^{\circ} \mathrm{C}$, respectively) and in $\mathrm{pH}(-0.759 \%$, and $-0.298 \%$ changes in area for $\mathrm{pHs} 2.8$, and 3.2, respectively), the amount of change of the peak area was less than $\pm 2.0 \%$. However, small changes in the mobile phase flow rate $(4.933 \%$, and $-4.206 \%$ changes in area for $0.95 \mathrm{ml} / \mathrm{min}$, and $1.05 \mathrm{ml} / \mathrm{min}$ respectively) can significantly affect the peak response. Thus, it is necessary to ensure that the HPLC pump operates properly and correctly. According to the results, the method showed a high level of suitability, specificity, linearity, accuracy, precision, repeatability, robustness, and reliable detection limit.

\section{Supplementary Data}

Supplementary data are available at the Journal home page.

\section{Acknowledgment}

Authors would like to thank Tofigh Daru Research and Engineering Company for financial and technical support of this work.

\section{Materials and methods}

\subsection{Experimental}

Chemicals containing potassium dihydrogen phosphate (PDP), ortho-phosphoric acid (OPA), and potassium chloride (PC), and acetonitrile (ACN) were prepared from Merck chemical company (Germany). Teriflunomide (TFN) was provided from the Chemical Synthesis Department of Tofigh Daru Research and Engineering Company (Tehran, Iran).

\subsubsection{Instrumentation}

The Shimadzu Prominence system (Shimadzu Corporation, Kyoto, Japan) Equipped with a LC20AD pump, a DGU-20A degassing system, a CTO-20A column oven and a SPD-20A UV-Vis detector, was used for all analysis. Also, the LabSolutions software version 5.51 was applied for processing and data analysis.

\subsubsection{Chromatographic conditions and sample preparation}

A C18, end-capped $(250 \times 4.6) \mathrm{mm}, 5 \mu \mathrm{m}$ liquid chromatography column was applied for both Assay and Related substance analysis. The mobile phase A was prepared by dissolving $2.74 \mathrm{~g}$ of PDP and $3.72 \mathrm{~g}$ of $\mathrm{PC}$ in water and further dilution to $1000 \mathrm{~mL}$ with water as solvent. Then, $\mathrm{pH}$ was adjust to 3.0 by adding OPA $85 \%$. Also, the mobile phase B was ACN (100\%). Also, a UV detector on the wavelength of $280 \mathrm{~nm}$ was used to record the chromatograms. The column temperature was maintained at $35^{\circ} \mathrm{C}$ and the injection volume was $20 \mu \mathrm{L}$. The sample solutions were prepared as following:

Test solution (a): Dissolve $10 \mathrm{mg}$ of the substance to be examined in the diluent (sonicate the solution if it is needed) and dilute to $10 \mathrm{~mL}$ with the same solvent $(1000 \mathrm{mg} / \mathrm{L})$.

Test solution (b): Dilute $1.0 \mathrm{~mL}$ of Test solution (a) to $50.0 \mathrm{~mL}$ with the diluent $(20 \mathrm{mg} / \mathrm{L})$.

Test solution (c): Dilute $1.0 \mathrm{~mL}$ of Test solution (b) to $20.0 \mathrm{~mL}$ with the diluent $(1 \mathrm{mg} / \mathrm{L})$. 
The injections were $20 \mu \mathrm{L}$ of the Blank solution, Test solution (c) and Test solution (a). To calculate the number of impurities, the peak areas of impurities in the chromatogram obtained with Test solution (a) and the peak area of principal peak in the chromatogram obtained with Test solution (c) were required. The concentration range of the solutions required for calibration curve preparation were $151.626 \mathrm{mg} / \mathrm{L}$ to $252.710 \mathrm{mg} / \mathrm{L}$.An end-capped C18 $(5 \mu \mathrm{m}, 4.6 \times 250 \mathrm{~mm})$ Hector chromatographic column was applied for the present reverse-phase HPLC system. Also, the elution program for the process was: $0.00 / 75,30.00 / 55,60.00 / 55($ time $(\mathrm{min}) / \mathrm{A} \%$ ) at the flow rate of $1.0 \mathrm{ml} / \mathrm{min}$. The solvent selected for dissolving and diluting of the sample was ACN, and the chromatograms have been recorded at $280 \mathrm{~nm}$. The column temperature was $35^{\circ} \mathrm{C}$, and volume of injection was $20 \mu \mathrm{L}$. The stock solution for the linearity study was prepared by dissolving the substance in acetonitrile on the concentration of $0.01561 \mathrm{~g}$ of TFN in $50.0 \mathrm{~mL}$ of diluents.

\subsection{Theoretical}

At the first step, a reasonable structure based on the usual predictions of the Gaussian 03 quantum chemical package ${ }^{23}$ was developed and undergone BOMD simulations. ${ }^{24,25}$ Then, some hypothetical structures were extracted from the output spectrum of the trajectory simulation. Then, those structures were designed as input files, and optimized to give the most stable system. Finally, the best system which was detected by optimization of the system at B3LYP/6-311G(d,p) level of theory, ${ }^{26,27}$ was set for the TD-DFT calculations ${ }^{28,29}$ to give the UV-visible spectrum at the mentioned level.

\section{References}

1 Patejdl R., Penner I. K., Noack T. K., Zettl U. K. (2016) Multiple sclerosis and fatigue: a review on the contribution of inflammation and immune-mediated neurodegeneration, Autoimmunity rev., 15(3) 210-220.

2 Yong V. W. (2002) Differential mechanisms of action of interferon- $\beta$ and glatiramer acetate in MS. Neurology, 59 (6) 802-808.

3 Kowarik M. C., Pellkofer H. L., Cepok S., Korn T., Kümpfel T., Buck D., Hemmer B. (2011) Differential effects of fingolimod (FTY720) on immune cells in the CSF and blood of patients with MS. Neurology, 76 (14) 1214-1221.

4 Mohajeri M., Sadeghizadeh M., Najafi F., Javan M. (2015) Polymerized nano-curcumin attenuates neurological symptoms in EAE model of multiple sclerosis through down regulation of inflammatory and oxidative processes and enhancing neuroprotection and myelin repair. Neuropharmacology, 99 156-167.

5 Kalincik T., Havrdova E. K., Horakova D., Izquierdo G., Prat A., Girard M., Ozakbas S. (2019) Comparison of fingolimod, dimethyl fumarate and teriflunomide for multiple sclerosis. $J$ Neurol Neurosurg Psychiatry, 90 (4) 458-468.

6 Gever J (June 4, 2012). Teriflunomide Modest Help but Safe for MS. medpage. Joint meeting of the Consortium of Multiple Sclerosis Centers and the Americas Committee for Treatment and Research in Multiple Sclerosis. Retrieved June 4, 2012

7 Drug Approval Package: Aubagio (teriflunomide) Tablets NDA \#202992". U.S. Food and Drug Administration (FDA). 5 November 2012.

8 Sobhani K., Garrett D. A., Liu D. P., Rainey P. M. (2010) A rapid and simple high-performance liquid chromatography assay for the leflunomide metabolite, teriflunomide (A77 1726), in renal transplant recipients. Am. J clinical pathology, 133 (3) 454-457.

9 Bhavya M., Prajapat P., Gohil Y. (2017) Development and validation of stability indicating RP-HPLC method for estimation of teriflunomide in active pharmaceutical ingredient, Pharma. Innov., 6 (9) 440-449.

10 Halima R., Rozek T., Hopkins A., Proudman S., Cleland L., James M., Wiese M. (2011) Quantitation of total and free teriflunomide (A77 1726) in human plasma by LC-MS/MS. J. pharma. Biomed. Anal., 55 (2) 325-331. 
11 Gao S., Duan M., Houk K. N., Chen M. (2020) Chiral Phosphoric Acid Dual-Function Catalysis: Asymmetric Allylation with $\alpha$-Vinyl Allylboron Reagents. Angewandte Chem. Int. Ed., 59 (26) 10540-10548.

12 a) Athavale S. V., Simon A., Houk K. N., Denmark S. E. (2020) Demystifying the asymmetryamplifying, autocatalytic behaviour of the Soai reaction through structural, mechanistic and computational studies, Nature chem., 12 (4) 412-423.; b) Woliński P., Kącka-Zych A., Demchuk O. M., Łapczuk-Krygier A., Mirosław B., Jasiński R. (2020) Clean and molecularly programmable protocol for preparation of bis-heterobiarylic systems via a domino pseudocyclic reaction as a valuable alternative for TM-catalyzed cross-couplings, J. Clean. Product., 275122086.

13 a) Bakherad M., Keivanloo A., Samangooei S., Omidian M. (2013) A phenyldithio carbazatefunctionalized polyvinyl chloride resin-supported $\mathrm{Pd}$ (II) complex as an effective catalyst for solvent-and copper-free Sonogashira reactions under aerobic conditions, J. Organomet. Chem., 740 78-82; b) Bakherad M., Keivanloo A., Omidian M., Samangooei S. (2014) Synthesis of pyrrolo [2, 3-b] pyrazines through Sonogashira coupling reaction of 5, 6-dichloropyrazine-2, 3-dicarbonitrile with hydrazine, phenylacetylene and various aldehydes, J. Chem. Res., 38 (12) 762-764.

14 Hecht K., Meyer H. P., Wohlgemuth R., Buller R. (2020) Biocatalysis in the Swiss manufacturing environment. Catalysts, 10 (12) 1420.

15 a) Rostami-Charati F., Hossaini Z., Sheikholeslami-Farahani F., Azizi Z., Siadati S. A. (2015) Synthesis of 9H-furo [2, 3-f] Chromene Derivatives by Promoting ZnO Nanoparticles. Comb. Chem. high throughput screen., 18 (9) 872-880; b) Hossaini Z., Rostami-Charati F., Ghambarian, M., Siadati, S. A. (2015) Synthesis of a new class of phosphonate derivatives using a three component reaction of trialkyl phosphites or triaryl phosphites in water, Phosphorus Sulfur Silicon Relat. Elem., 190 (7) $1177-1182$.

16 a) Siadati S. A. (2016) Beyond the alternatives that switch the mechanism of the 1, 3-dipolar cycloadditions from concerted to stepwise or vice versa: a literature review. Prog. React. Kinet. Mech., 41 (4) 331-344; b) Siadati S. A. (2016) A Theoretical Study on Stepwise-and Concertedness of the Mechanism of 1, 3-Dipolar Cycloaddition Reaction Between Tetra Amino Ethylene and Trifluoro Methyl Azide. Comb. Chem. high throughput screen., 19 (2) 170-175; c) Siadati S. A., Nami N., Zardoost M. R. (2011) A DFT Study of Solvent Effects on the Cycloaddition of Norbornadiene and 3, 4-Dihydroisoquinoline-N-Oxide. Prog. React. Kinet. Mech., 36 (3) 252-258;

17 a) Siadati S. A., Amini-Fazl M. S., Babanezhad E. (2016) The possibility of sensing and inactivating the hazardous air pollutant species via adsorption and their [2+3] cycloaddition reactions with C20 fullerene, Sens. Actuator B Chem., 237 591-596; b) Siadati S. A., Nami N. (2016) Investigation of the possibility of functionalization of C20 fullerene by benzene via Diels-Alder reaction. Physica E: Low-dimens. Sys. Nanostruct., 84 55-59.

18 a) Kula K., Dobosz J., Jasiński R., Kącka-Zych A., Łapczuk-Krygier A., Mirosław B., Demchuk O. M. (2020) [3+ 2] Cycloaddition of diaryldiazomethanes with (E)-3, 3, 3-trichloro-1-nitroprop-1-ene: An experimental, theoretical and structural study. J. Mol. Struct., 1203 127473; b) Siadati S. A., Mirabi A. (2015) Diels-Alder versus 1, 3-dipolar cycloaddition pathways in the reaction of C20 fullerene and 2-furan nitrile oxide, Prog. React. Kinet. Mech., 40 (4) 383-390; c) Jasiński R., Dresler E. (2020) On the Question of Zwitterionic Intermediates in the [3+2] Cycloaddition Reactions: A Critical Review, Organics, 1 (1) 49-69.

19 a) Katakam L. N. R., Dongala, T. (2020) A novel RP-HPLC refractive index detector method development and validation for determination of trace-level alcohols (un-sulfated) in sodium lauryl sulfate raw material, Biomed. Chromato., 34 (7) 4827; b) Siadati S. A., Rezvanfar M. A., Payab M., Beheshti, A. (2021) Development and validation of a short runtime method for separation of trace amounts of 4-aminophenol, phenol, 3-nitrosalicylic acid and mesalamine by using HPLC system, Curr. Chem. Lett., doi: 10.5267/j.ccl.2020.12.002; c) Dadras, A., Rezvanfar, M. A., Beheshti, A., Naeimi, S. S., Siadati, S. A. (2021) An Urgent Industrial Scheme both for Total Synthesis, and for Pharmaceutical Analytical Analysis of Umifenovir as an Anti-Viral API for Treatment of COVID19. Comb. Chem. High Throughput Screen., DOI:10.2174/1386207324666210203175631. 
20 ICH Harmonized Tripartite Guideline, Impurities in new drug substances, Q3A(R2), Current Step 4 version, dated 25 October 2006. http:/www.ich.org/fileadmin /Public_Web Site /ICH Products/Guidelines/Quality/Q3A_R2/ Step4/Q3A_R2_Guideline.pdf (accessed December, 2016).

21 Armbruster D. A., Tillman M. D., Hubbs L. M. (1994) Limit of detection (LQD)/limit of quantitation (LOQ): comparison of the empirical and the statistical methods exemplified with GC-MS assays of abused drugs. Clinical chem., 40 (7) 1233-1238.

22 Ermer J., Arth C., De Raeve P., Dill D., Friedel H. D., Höwer-Fritzen H., Maegerlein M. (2005) Precision from drug stability studies: Investigation of reliable repeatability and intermediate precision of HPLC assay procedures. J pharma. Biomed. Anal., 38 (4) 653-663.

23 Frisch M.J., Trucks G.W., Schlegel H.B., Scuseria G.E., et al. GAUSSIAN 03, Gaussian Inc. Pittsburgh, PA, 2003.

$24 \mathrm{Pu}$, M., Privalov, T. (2015) Ab initio molecular dynamics with explicit solvent reveals a two-step pathway in the frustrated Lewis pair reaction, Chem.-A Europ. J., 21 17708-17720.

25 Li C., Requist R., Gross E. K. U. (2018) Density functional theory of electron transfer beyond the Born-Oppenheimer approximation: Case study of LiF. J. chem. phys., 148 (8) 084110.

26 Becke, A.D. (1988) Density-functional exchange-energy approximation with correct asymptotic behavior, Phys. Rev. A, 38 3098-3100.

27 Delchev V., Nenkova, M. V. (2008) Theoretical Modeling of the Ground State Intermolecular Proton Transfer in Cytosine: DFT Level Study, Acta. Chim. Slov., 55 132-137.

28 Blase X., Duchemin I., Jacquemin D. (2018) The Bethe-Salpeter equation in chemistry: relations with TD-DFT, applications and challenges, Chem. Soc. Rev., 47 (3) 1022-1043.

29 Khan I. M., Alam K., Alam M. J. (2020) Exploring charge transfer dynamics and photocatalytic behavior of designed donor-acceptor complex: characterization, spectrophotometric and theoretical studies (DFT/TD-DFT), J. Mol. Liquid, 310113213. 
(C) 2021 by the authors; licensee Growing Science, Canada. This is an open access article distributed under the terms and conditions of the Creative Commons Attribution (CC-BY) license (http://creativecommons.org/licenses/by/4.0/). 